\title{
41. LA REFORMA CONSTITUCIONAL Y LAS CLÁUSULAS DE INTANGIBILIDAD
}

\author{
M. ${ }^{a}$ VICTORIA GARCIA-ATANCE GARCÍA \\ Profesora Titular de Derecho Constitucional \\ UNED
}




\section{SUMARIO}

I. Opción POR UN PODER de Reforma REAL.-II. Perfil AMBIVALENTE de LA INSTITUCIÓN DE REFORMA CONSTITUCIONAL. - III. VALORACIONES DEL ARTÍCULO 168 CE POR LA DOCTRINA. -IV. EN EL ÁMBITO DEL DERECHO COMPARADO.-Aplicación práctica del precepto. Propuesta alternativa. 


\section{LA REFORMA CONSTITUCIONAL Y LAS CLÁUSULAS DE INTANGIBILIDAD}

POR

M. ${ }^{a}$ VICTORIA GARCÍA-ATANCE GARCÍA

Profesora Titular de Derecho Constitucional

UNED

I. OPCIÓN POR UN PODER DE REFORMA REAL

Quiero, en primer lugar, manifestar mi opción por un poder de reforma constitucional real, esto es, limitado jurídicamente.

Para justificar, en consecuencia, la propuesta de texto alternativo al artículo $168 \mathrm{CE}$, he de partir de una concepción de la actividad de reforma que compatibilice la tendencia irrenunciable al cambio, al que se encuentran impelidos los textos constitucionales con la idea de permanencia, con el objeto de que el poder de revisión se configure como auténtico poder constituido, esto es, limitado jurídicamente por el Derecho positivo, y no como una nueva manifestación del poder constituyente, que es, en defini-

- tiva el que se activa en el supuesto de reforma total o revisión de alguno de los principios configuradores del núcleo sustancial.

En este sentido, comparto el principio acuñado por el constitucionalismo revolucionario, en virtud del cual el poder constituyente de un día no puede poner trabas al poder constituyente del futuro, pero introduciendo un significativo matiz — como afirma DE VEGA ${ }^{1}$ - siempre que ese poder del porvenir se configure como un poder constituyente $-y$ por tanto res

1 P. DE VEGA: La reforma constitucional y la problemática del poder constituyente. Madrid. Edit. Tecnos, 1985, pág. 29. 
facti, non iuris- y no un poder constituido, que es, en definitiva, el que se activa en el supuesto de reforma constitucional, quedando limitado en su actividad al estar juridificado de origen.

\section{PERFIL AMBIVALENTE DE LA INSTITUCIÓN DE REFORMA CONSTITUCIONAL}

En coherencia con esta consideración inicial, concibo las actividad de reforma como garante de la continuidad del orden constitucional al posibilitar las precisas transformaciones, pero además garante asimismo del contenido o núcleo sustancial e irreductible, como afirmaba CRISOFULLI, que permite seguir identificando un orden constitucional concreto, y cuya modificación no se reduciría a una simple reforma del orden constitucional, sino a una supresión del mismo, como diferencia SCHMITT ${ }^{2}$. En consecuencia cabe reconocer un perfil ambivalente que proyecta la institución de reforma en la dialéctica permanencia-cambio, que deriva de su función transformadora, pero compatibilizándola a su vez con la función de defensa no jurisdiccional del orden constitucional, que tal instituto asume, como ha afirmado DE OTTO PARDO ${ }^{3}$.

\section{VALORACIÓN DEL ARTÍCULO 168 CE POR LA DOCTRINA}

Aunque algún sector de la doctrina, representado entre otros por CONTRERAS ${ }^{4}$, diferencia entre el concepto de límites expresos al poder de reforma de las claúsulas de intangibilidad, me inclino, sin embargo, a no diferenciar entre límites expresos al poder de reforma y dichas cláusulas, compartiendo en este sentido la posición asumida por DE VEGA 5, por considerar que en los dos casos estamos, de cualquier modo, ante una limitación a la actividad revisora del texto constitucional, y cuya diferenciación dependerá del grado de superación de tal limitación, distinguiendo entre límites absolutos o relativos.

2 C. Schmit: Teoría de la Constitución. Madrid. Alianza Edit., 1982, pág. 120.

3 I. DE Otto PARDo: Defensa de la Constitución y partidos políticos. Centro de Estudios Constitucionales, Madrid, 1985, pág. 34.

4 M. Contreras: Estudios sobre la Constitución Española de 1978. Dirige Manuel Fiamírez, Zaragoza. Facultad de Derecho de Zaragoza, 1979, pág. 417.

5 P. DE VEGA: La reforma..., op. cit., pág. 242. 
Son dos los aspectos especialmente claves que conviene plantear en el artículo 168 CE: de una parte el que se refiere a la no limitación al poder de reforma, $y$, de otra, el sincretismo de materias sumamente dispares en lo relativo a su trascendencia constitucional, en un mismo procedimiento, y configurando, en definitiva un artículo de muy desafortunada redacción.

En lo que concierne al primero de los aspectos, la doctrina no se manifiesta pacífica al enjuiciar este artículo, al reflejarse en él la problemática a la que aludimos, ya que prevé la posible reforma total o supresión de la Constitución.

A pesar del carácter abierto del procedimiento de reforma contemplado en nuestra Conśtitución en lo que se refiere a límites y que no suscita grandes dudas sobre la inexistencia aparente de límites textuales absolutos, sin embargo, no por ello ha quedado zanjada la cuestión, originando amplia controversia doctrinal.

El estado de la cuestión en la actualidad se cifra básicamente en dos tendencias contrapuestas. De una parte, el sector doctrinal que se inclina a favor de una actividad de reforma sin sujeción a límite absoluto alguno en razón de la materia representada por PÉREZ ROYO ${ }^{6}$, que no sólo no los justifica, sino que considera además que el auténtico problema del artículo 168 reside en la grave dificultad — dado su grado de rigidez- para acometer reformas convenientes en la norma constitucional, propiciándose con ello un margen excesivamente amplio a la discrecionalidad del Tribunal Constitucional, obligándole a entrar en cuestiones de tipo político.

También se ha objetado por un amplio sector doctrinal la falta de eficacia de estas cláusulas de intangibilidad, cuando el desenvolvimiento de la vida constitucional deja de ser pacífico, dependiendo, en consecuencia, su eficacia real del respeto que profesen las diferentes fuerzas políticas preponderantes.

De otra parte, un sector doctrinal representado básicamente por $\mathrm{DE}$ VEGA, JIMÉNEZ CAMPO, DE OTTO PARDO y CONTRERAS, se inclinan, contrariamente, por la admisibilidad de algún tipo de limitación al poder de reforma, si bien, divergen entre sí tanto en la justificación de su existencia, como en la concreción de dicha limitación.

6 J. Pérez Royo: La reforma de la Constitución. Madrid. Congreso de los Diputados, 1987, pág. 211: para el supuesto de materias reservadas al legislador que reforma la Constitución, pero ante la dificultad procedimental para su actuación, obligue a intervenir al intérprete constitucional. 
JIMÉNEZ CAMPO 7 justifica su admisibilidad, como medio para garantizar la supremacía de la Constitución frente a su revisión.

De igual modo, CONTRERAS ${ }^{8}$ se manifiesta a favor de la conveniencia de reconocer alguna limitación al poder de reforma, lo que le conduce a vislumbrar una cláusula de intagibilidad en el artículo 169, e incluso una limitación -si bien de orden implícito- en el artículo 10-1, que afectaría al ámbito de los derechos fundamentales.

Por otro lado, DE VEGA ${ }^{9}$ se inclina decididamente por el reconocimiento de una actividad revisora limitada, en aras a la distinción entre la competencia omnipotente que deriva del poder constituyente - cuya manifestación de hecho, escapa a toda pretensión juridificada-, y la competencia del poder constituido, incompetente para cercenar la propia base jurídica que le sirve de fundamento.

En la misma línea de aceptación de límites en nuestra norma constitucional se manifiesta DE OTTO PARDO ${ }^{10}$, que justifica la necesidad de una limitación a la actividad de reforma desde su consideración de función de defensa no jurisdiccional del orden constitucional que dicha actividad asume.

Desde esta perspectiva doctrinal que se manifiesta, de un lado, contra la admisibilidad de límites a la actividad de reforma - ya sea por negarle valor jurídico a las cláusulas de intangibilidad ${ }^{11}$, o bien por juzgar innecesaria o ineficaz la presencia de tales límites expresos ${ }^{12}-$ y de otra parte a favor de la admisibilidad de dichos límites, convenimos con el sector de la doctrina que, sin perjuicio de la relativa eficacia real de los límites absolutos, como señala PEREIRA MENAUT ${ }^{13}$, apoya la limitación del poder de reforma a través de la defensa de éstos. criterios:

A mi juicio esta posición cabe argumentarse desde los siguientes

7 J. Jiménez CAMPo: «El Título $\mathrm{X}$ de la Constitución», en $R D P, \mathrm{n} .^{\circ} 7$, UNED, 1980, pág. 92. 417 y 419.

8 M. Contreras: Estudios sobre la Constitución española..., op. cit., págs.

9 P. DE VEGA: La reforma constitucional..., op. cit., pág. 28.

10 I. DE OTto PARDO: Defensa de la Constitución y partidos..., op. cit., pág. 34.

11 Jellinek, Pergolesi, Biscaretti di Ruffia, Vanosi, entre otros.

12 Cuya observancia dependerá siempre del respeto que profesen las fuerzas políticas a la norma constitucional.

13 A.C. Pereira Menaut: En defensa de la Constitución. Pamplona. Ediciones Universidad de Navarra, 1986, pág. 108. 
- Por la dispar naturaleza del poder constituyente y poder constituido. La determinación de zonas exentas a la acción del poder de revisión en la Constitución como afirma DE VEGA ${ }^{14}$ equivale a reconocer la naturaleza constituida o limitada del poder de reforma. Desde esta consideración, este poder de reforma resultará incompetente tanto para suprimir la Constitución -en los supuestos de reforma total- como para reformar parcialmente algunos de los contenidos que configuran el núcleo sustancial de la Constitución, ya que, como afirma BURDEAU ${ }^{15}$ el poder constituido es incompetente para cercenar el fundamento jurídico que le sirve de base, e incompetente, en definitiva, para alterar la decisión política fundamental asumida por el constituyente, que preconiza SCHMITT ${ }^{16}$.

- Por la supremacía de la norma constitucional respecto a las normas de revisión, existiendo entre ellas una graduación jerárquica que impediria la desconstitucionalización de aquélla por una ley de revisión, como señala MORTATI ${ }^{17}$, so pena de pervertir el ordenamiento jurídico sólo soslayable a través del reconocimiento de límites a la actividad revisora.

- Por el principio de no contradicción entre disposiciones de igual rango preconizada por ESPÓSITO ${ }^{18}$, constituyendo una incongruencia admitir la validez de ciertas disposiciones que establecen impedimentos de cualquier orden a la capacidad revisora (art. $169 \mathrm{CE}$ ) y negar, a su vez, tal validez a disposiciones que, emanando de la misma fuente, tengan el mismo rango jerárquico.

- Por la función de defensa no jurisdiccional del orden constitucional que asume la actividad de reforma cuando se contemplan límites a la misma, pues a través de los cuales el constituyente pretende identificar con mayor o menor precisión un núcleo constitucional irreductible, objeto de la defensa constitucional de orden no jurisdiccional.

- Para romper el sincretismo de materias que son objeto indiscriminado del procedimiento de reforma superagravado contemplado en el

14 P. DE VEGA: La reforma constitucional..., op. cit., pág. 255.

15 G. Burdeau: Traité de Science Politique, Deuxième édition, tome IV, Paris. Librairie Générale de Droit et Jurisprudence, 1969, pág. 253.

${ }_{16}$ C. SCHMITT: Teoría de la Constitución..., op. cit., pág. 46.

17 C. MoRTATI: Raccolta di Scritt, vol. II, Studi sulla Costituzione e sulla revisione costituzionale. Publicazioni dell'istituto di studi giuridici della Facoltá di Scienze Politiche de I'Universitá di Roma. Milano, Giuffrè editore, 1972, págs. 17-19.

18 C. Espósıto: La validitá delle leggi, Milano, Giuffrè editore, 1964, pág. 169. 
artículo $168 \mathrm{CE}$, posibilitando, con la diferenciación específica entre materia sustanciales, que definen el núcleo identificador de la Constitución y otros aspectos que no son trascendentales a efectos de protección de la fórmula política y no justifican un procedimiento tan extraordinariamente complejo para su reforma.

- Para evitar recurrir a la indagación de límites implícitos de orden metajurídico - en aras a la seguridad jurídica - que garanticen la subsistencia del núcleo identificador de la Constitución, evitando su des-sustancialización, como señalaba LUCAS VERDÚ.

- Porque la supremacía constitucional revela en la actualidad como aduce DE VEGA ${ }^{19}$ - un carácter ideológico irrenunciable, integrador del concepto político de Constitución, y cuya falta de límites al poder de reforma en nuestra Constitución, hace pensar -como afirmaba JIMÉNEZ CAMPO ${ }^{20}$ - en una desideologización de la misma, lo cual resulta contradictorio con la idea de supremacía material que debe alentar al texto constitucional.

De todo lo referido en estos argumentos, cabe señalar que la finalidad última de la observancia de límites expresos tiene por objeto garantizar la subsistencia de los supuestos ideológicos y valorativos que identifican el régimen político definido en nuestra Constitución.

\section{EN EL ÁMBITO DEL DERECHO COMPARADO}

El Derecho comparado no escatima precedentes en la contemplación de límites expresos absolutos o cláusulas de intangibilidad como es el supuesto de la Constitución de EE.UU. de América, cuyo artículo $V$ in fine sustrae de la actividad revisora lo referente a la igualdad de sufragio de los diferentes Estados ante el Senado.

Asimismo la Constitución francesa de 1958 introduce en su artículo 89 in fine una cláusula de intangibilidad a la actividad de reforma en lo que afecta a la forma republicana de gobierno, lo que es asimismo predicable de la Constitución italiana de 1947 en su artículo 139. 
Por otra parte, es asimismo reconocida otra cláusula de intangibilidad en la Ley Fundamental de Bonn, en cuyo art. 79-3 prohibe toda alteración de la Constitución en lo que afecta a la división de la Federación en Estados, o al principio de cooperación de los Estados en la legislación, así como a los principios de los artículos $1 .^{\circ}$ y $2 .^{\circ 21}$.

\section{Aplicación práctica del precepto}

Aunque la realidad es que hasta el presente todas las cautelas argumentadas, en vía teórica, respecto a la inexistencia de límites y el consecuente riesgo de vulneración de determinadas materias, no se ha traducido en la práctica dada la inaplicación del precepto durante estos 13 años, sin embargo, los vientos revisionistas que soplan como consecuencia de los acuerdos de Maastricht, hacen preciso su replanteamiento. A este respecto, la propuesta como texto alternativo que sugiero es la siguiente.

\section{Propuesta alternativa}

El resultado lamentablemente híbrido de la redacción del artículo 168 hay que atribuirlo seguramente al recalcitrante interés de evitar introducir cláusulas de intangibilidad, lo que origina una dificultad excesiva en el procedimiento de reforma, que si por una parte hace casi inviable la modificación de algunos artículos incluidos en los títulos contemplados en el 168, de relativa importancia, tampoco salva del poder de revisión otros aspectos que configuran aspectos sustanciales que deben quedar al margen de la actividad constituida de reforma.

Sin atreverme a reflejar un texto alternativo formalmente redactado, lo que sí haré será sugerir ciertos criterios que a mi juicio conviene tener presentes en un posible texto alternativo a la actual redacción.

En primer lugar, la contemplación de límites expresos, como condición previa a la redacción del artículo $168 \mathrm{CE}$.

21 Art. 1. : Sobre la intangibilidad de la dignidad humana y la inviolabilidad de los derechos humanos.

Art. 2. : Sobre la forma republicana federal, soberanía popular, sumisión de todos los poderes a la Constitución y al derecho y la resistencia del pueblo frente a cualquier atentado contra ese orden. 
En segundo lugar, la desaparición de la supresión o reforma total de la norma por vía de la actividad de reforma constitucional.

En tercer lugar, considero conveniente la observancia de cláusulas de intangibilidad en lo que concierne a los siguientes preceptos constitucionales:

Uno de ellos afectaría al artículo 1 CE:

- El artículo 1-1 que propugna como valores superiores del ordenamiento jurídico la libertad, la justicia, la igualdad y el pluralismo político.

- La titularidad de la soberanía nacional (art. 1-2).

- La Monarquía parlamentaria como forma política del Estado español (art. 1-3).

Asimismo me inclino por la integración en el ámbito de las materias intangibles del artículo 10-1, que en la actualidad, y sorprendentemente, queda fuera de este ámbito, a pesar de ser proclamada constitucionalmente la dignidad de la persona y sus derechos inherentes como "fundamento del orden político y paz socialn.

Desde esta propuesta se conseguiría una triple finalidad:

a) Una vez extrapolados, dotándoles de carácter intangible, los principios que definen el núcleo sustancial de la Constitución, se torna innecesario el procedimiento superagravado del art. 168 CE para modificar estas materias.

b) Se permite una reforma no tan rígida para aquellas materias de importancia relativa que en la actualidad caen injustificadamente dentro de la esfera del procedimiento agravado, las cuales pasarían a ser objeto de revisión por el procedimiento ordinario.

c) Se terminaría con la contradicción que presenta la actual redacción del art. $168 \mathrm{CE}$, al no amparar dentro de las materias de tratamiento de modificación y superagravada al propio procedimiento de reforma 
constitucional, pues de poco sirven todas las cautelas contempladas en el mismo, si a fin de cuentas pueden ser superadas modificándose el procedimiento agravado por vía del procedimiento ordinario contemplado en el 167 CE. 